\title{
Perioperative Challenges during Emergency Spine Surgery in a Patient with Right Atrial Thrombus
}

\author{
Siddharth Chavali ${ }^{1}$, Ruhi Mamualiya ${ }^{1}$ Hirok Roy $^{1}$ \\ ${ }^{1}$ Department of Neuroanaesthesiology and Critical Care, All India \\ Institute of Medical Sciences, New Delhi, India
}

J Neuroanaesthesiol Crit Care 2021;8:158-160.

A 50-year-old male patient, weighing approximately $60 \mathrm{~kg}$, presented with a history of excruciating lower back pain of 12 hours' duration, associated with acute loss of bladder and bowel control. This was preceded by approximately a month of progressively increasing weakness in both lower limbs. Three years ago he underwent radical cystoprostatourethrectomy for carcinoma of the urethra. An emergency computed tomographic (CT) scan of the spine revealed a compression fracture of the thoracic (T10) vertebra. A diagnosis of malignant compressive fracture was made. In view of acute presentation of cauda equina syndrome, an urgent surgical decompression and fixation was planned.

The patient was awake and alert, and oriented to time, place and person. Vitals were within normal ranges, and all hematological investigations were found to be within normal limits. Considering the history of progressive paraplegia given by the patient, we considered it prudent to perform a screening 2D echocardiogram as well as a lower limb color Doppler examination. Lower limb imaging was unremarkable for any pathology; however, echocardiography revealed a thrombus originating from the inferior vena cava, extending into the right atrium, which was approximately $3.5 \times$ $3.2 \times 2.9 \mathrm{~cm}$ in size ( - Fig. 1). Left ventricle was found to be normal, with preserved ejection fraction, and all valves were seen to be within normal limits.

We were greatly concerned with regard to the safe induction and maintenance of anesthesia, especially since the surgery was to be performed in the prone position with the thrombus in situ. The patient was volume loaded with $500 \mathrm{~mL}$ of colloid and one liter of crystalloid. The left radial artery was cannulated prior to induction, and anesthesia was induced slowly with a regimen of etomidate, fentanyl, and rocuronium. This was followed by central venous
Address for correspondence Girija P. Rath, MD, DM, Department of Neuroanaesthesiology and Critical Care, Neurosciences Centre, All India Institute of Medical Sciences, New Delhi 110029, India (e-mail: girijarath@aiims.edu).

cannulation which was uneventful. The patient was carefully turned prone, and the surgery proceeded uneventfully. At the end of the procedure, which lasted 3 hours, the patient was turned supine, and the trachea was extubated after reversal of residual neuromuscular blockade. The remainder of his hospital stay was uneventful, and he was advised to undergo mechanical thrombectomy.

Deep venous thrombosis and pulmonary embolisms are complications frequently seen in patients who sustain high-cervical spinal cord trauma. Various measures to prevent their occurrence have been suggested, which include pneumatic compression, treatment with low-molecular weight heparin, inferior vena cava filter placement, etc. ${ }^{1,2}$ In this particular case, the emergent nature of the surgery precluded the use of any such measure. Moreover, the risk-benefit ratio of the surgery remains debatable, given the presentation of the patient with the above-mentioned scenario. The patient and relatives, in the presence of the operating team, were explained in detail, and necessary consent was taken. It would have been ideal had the patient undergone emergency mechanical thrombectomy prior to the definitive surgery which is also of emergent nature. It also suggested the fact that this particular scenario might help respective healthcare personnel plan surgery in resource-constrained situations. We would like to re-emphasize that patients presenting with cauda equina syndrome should be asked carefully regarding the duration of symptoms; and those with a history of paraparesis should undergo routine screening echocardiograms to rule out venous thromboembolism. Meticulous planning and careful management of intravascular volume status and hemodynamics may help patients overcome complications, in case the preventive/ definitive measures for subsequent thromboembolism are not available.
Published online

September 2, 2020
DOI https://doi.org/

$10.1055 / \mathrm{s}-0040-1715921$

ISSN 2348-0548. (c) 2020. Indian Society of Neuroanaesthesiology and Critical Care.

This is an open access article published by Thieme under the terms of the Creative Commons Attribution-NonDerivative-NonCommercial-License, permitting copying and reproduction so long as the original work is given appropriate credit. Contents may not be used for commercial purposes, or adapted, remixed, transformed or built upon. (https://creativecommons.org/licenses/by-nc-nd/4.0/).

Thieme Medical and Scientific Publishers Pvt. Ltd. A-12, 2nd Floor, Sector 2, Noida-201301 UP, India 


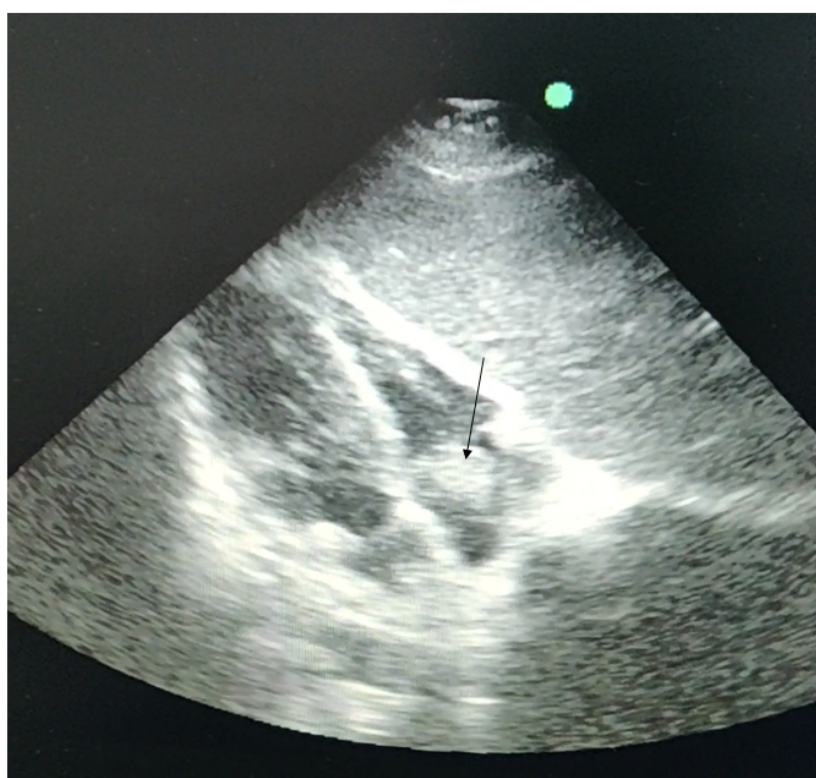

Fig. 1 Transthoracic echocardiogram shows apical four-chamber view, showing ball-like thrombus (arrow) in the right atrium.

\section{Conflict of Interest}

None declared.

\section{References}

1 Dhall SS, Hadley MN, Aarabi B, et al. Deep venous thrombosis and thromboembolism in patients with cervical spinal cord injuries. Neurosurgery 2013;72(Suppl 2):244-254

2 Eastern Association for the Surgery of Trauma. Venous thromboembolism: role of vena cava filter in the prophylaxis and treatmentofpe-practicemanagementguideline.Availableat:https:// www.east.org/education/practice-management-guidelines/ venous-thromboembolism-role-of-vena-cava-filter-in-theprophylaxis-and-treatment-of-pe. Accessed July 22, 2020 
